\title{
Relationship between Neutrophil to Lymphocyte Ratio with Diaphragm Thickness in Critical Patients
}

\author{
Agustina Haloho ${ }^{1,2 \#}$, Rudyanto Sedono ${ }^{2}$, Adhrie Sugiarto ${ }^{2}$ Zulkifli $^{1}$ \\ ${ }^{1}$ Department of Anesthesiology and Intensive Care, Faculty of Medicine Universitas Sriwijaya, Mohammad \\ Hoesin Hospital, Palembang - Indonesia \\ 2 Department of Anesthesiology and Intensive Care, Faculty of Medicine Universitas Indonesia, Cipto \\ Mangunkusumo Hospital, Jakarta - Indonesia \\ ${ }^{\#}$ Corresponding author E-mail : haloho1968@gmail.com
}

Received : January $17^{\text {th }} 2020$

Accepted : March $24^{\text {th }} 2020$

\begin{abstract}
Background

The cause of weaning failure is multifactorial. One of the causes was Ventilator Induced Diaphragm Dysfunction (VIDD) due to thinning process of the diaphragm thickness. Decreased diaphragm muscle mass might occur due to inflammatory process.

Methods

The study was an observational analytic study from September 2018 to January 2019 in Mohammad Hoesin Hospital, Palembang - Indonesia. Ethical appoval for the study was obtained from Ethics Committee and subjects were recruited after signing the informed consents. Only 30 subjects were involved in the end of the study. About $6 \mathrm{~mL}$ of blood sample from cubital vein was withdrawn from each subject to measure neutrophils and lymphocytes. Patients' diaphragm thickness was measured by using ultrasonography on 0th, 3rd, 5th day. Collected data were then analyzed with STATA 15.

\section{Results}

The chi-square test showed that the relationship of NLR (neutophil to lymphocyte ratio) of the $0^{\text {th }}$ day to the decrease in diaphragm thickness on the $3^{\text {rd }}$ day was not significant $(\mathrm{p}=0.254)$, while the decrease in diaphragm thickness on the $5^{\text {th }}$ day was significant $(p=0.015)$. Subjects with initial NLR values $>7$ had a significant higher risk of having decreased diaphragm thickness compared to subjects with initial NLR values $\leq 7$ ( $R R=1.62(0.99$ 2.64); p-value $=0.003$ ).

Conclusion

Neutrophil to lymphocyte ratio affected the decrease of diaphragm thickness in patients using mechanical ventilation.
\end{abstract}

Keywords: diaphragm thickness, neutrophil to lymphocyte ratio, mechanical ventilation 


\section{ISSN 25980580}

\section{Introduction}

Mechanical ventilation (MV) is utilized to provide adequate ventilation and oxygenation in critical patients. It is required to achieve normal arterial blood gas levels and acid-base balance. ${ }^{1,2}$ Patients should be weaned from MV when they are stable and ready to be released from Intensive Care Unit (ICU) into regular wards. MV weaning is a gradual process to reduce the ventilatory support and to prepare the lungs functioning normal again. However, weaning process might fail due to several conditions and failure to wean is an independent risk factor for mortality in critical care patients., ${ }^{3,4}$ Ventilator Induced Diaphragm Dysfunction (VIDD) is one of the causes. It occurs due to a decrease of diaphragm thickness which affects inspiratory pressures. ${ }^{5,6,7} \mathrm{Kim}$ et al. (2011) found that patients with diaphragmatic dysfunction showed a higher incidence of weaning failure, longer duration of MV use, and ICU treatment than patients with normal diaphragmatic function. ${ }^{8}$

Diaphragm thickness in sagittal plane view can be measured by positioning the ultrasound transducer on midaxillary line in $8^{\text {th }}$ or $9^{\text {th }}$ intercostal space. ${ }^{9}$ Changes in diaphragm thickness during inspiration of less $20 \%$ can be defined as paralyzed diaphragm. ${ }^{10}$ Jaber et al. (2011) stated that there was a significant correlation between diaphragm atrophy and duration of MV use $(r=0.53)$ in the short-term group and a weak correlation $(P=0.39)$ in the long-term group (>6 days). ${ }^{11}$

Critical patients suffer great inflammation. The inflammatory process causes an increase in proteolysis and a decrease in protein synthesis which result in a decrease of diaphragm muscle. Inflammatory process can be detected by neutrophil to lymphocyte ratio (NLR). Absolute lymphocytopenia value (lymphocyte count <1x109/1) is a systemic response to infection. De Jager et al. (2010) found that that NLR serum had a specificity of $63 \%$ and sensitivity of $77.2 \%$ to diagnose bacteremia, thus it was a better predictor than C-reactive protein (CRP) levels, leukocytes, and neutrophils serum. ${ }^{12}$ Yoon et al. (2013) also found that the role of NLR (AUC $=0.95$ ) was useful and better than CRP $($ AUC $=0.83) .{ }^{13}$ Based on those reasons, this study aims to find the relationship between NLR with diaphragm thickness of critical patients using MV in ICU. 
ISSN 25980580

\section{Methods}

This was an observational analytic study aimed to find the relationship between NLR with diaphragm thickness of critical patients using MV in ICU. It was conducted from September 2018 to January 2019 in Mohammad Hoesin Hospital, Palembang - Indonesia. Ethical appoval for the study was obtained from Ethics Committee (No. $143 /$ kepkrsmhfkunsri/2018) and the study was also retrospectively registered in ClinicalTrials.gov (NCT04014439).

Only 30 subjects were involved in the end of the study. Subjects were critical patients aged 17-70 years old in Intensive Care Unit, Mohammad Hoesin Hospital, Palembang Indonesia who used mechanical ventilation since the $0^{\text {th }}$ day for more than five days as predicted with quick Sepsis-related Organ Failure Assessment (qSOFA) and clinical judgement.[14] Patients with special conditions such as neuromuscular diseases, diaphragm malformations, using non-invasive ventilation before mechanical ventilation, had a history of tracheostomy, and had been hospitalized in ICU in the last 12 months before the study, were excluded from the study.

This study began after ethical clearance was approved by Ethics Committee of Health Research in Mohammad Hoesin Hospital, Palembang - Indonesia. Patients who fulfilled the criteria and allowed by their families after signing the informed consent forms to participate in the study. Patients and/or their relatives were fully explained about the study. About $6 \mathrm{~mL}$ of blood sample was withdrawn from cubital vein on each subject by using vacuum tube without anticoagulants. The blood samples were then centrifuged (3500 rpm for 20 minutes) to separate serum and plasma. To measure the neutrophils and lymphocytes, the serums were processed with abbott ${ }^{\circledR}$. Patients' diaphragm muscle mass were measured by using ultrasonography (USG) on the $0^{\text {th }}, 3^{\text {rd }}$, and $5^{\text {th }}$ day. Patients were in semirecumbent position and linear probe $10 \mathrm{MHz}$ were put between medial axillary line and anterior axillary line on $8^{\text {th }}-9^{\text {th }}$ intercostal space to visualize the diaphragm muscle mass.

This study was aimed to find the relationship between neutropil to lymphocyte ratio (NLR) with diaphragm thickness of critical patients using mechanical ventilation in Intensive Care Unit. The outcome was to examine the significance between NLR level with diaphragm 
thickness on the third day and fifth day of patients' admission in ICU. The cut-off used in this study was 7, for NLR, and $2 \mathrm{~mm}$, for diaphragm thickness.

This study was specifically designed to observe and measure critically ill patients with mechanical ventilation in Intensive Care Unit who met the eligible criteria. Sample size was measured according to "Rules of Thumb". The regulation stated that sample size should be ten times larger than the varables. Thus, samples required for this study were 30 .

Collected data were analyzed with STATA 15. Descriptive analysis was done to measure the subjects' characteristics, involving gender, age, and body mass index (BMI). Bivariate analyses with Chi-square test were performed to find the relation between neutrophil to lymphocyte ratio and diaphragm thickness, as those variables were classified as high and low with specific cut-off value (7, for NLR, and $2 \mathrm{~mm}$, for diaphragm thickness). Multivariables analysis with General Estimation of Equation was also performed to measure the repetitive values in differcnt measurements $\left(0^{\text {th }}\right.$ day, $3^{\text {rd }}$ day, and $5^{\text {th }}$ day $)$ involving diaphragm thickness and neutrophil to lymphocyte ratio. Results were stated as significant if p-value less than 0.05 .

\section{Results}

In the beginning, 48 subjects were recruited. In the end of the study, only 30 subjects were included since 18 of them were dropped out due to loss of follow-up. The demographic characteristics of the subjects can be seen in Table 1.

\section{Table 1. Characteristics of Research Subjects}

\begin{tabular}{ll}
\hline Age (years) & $11(36.67 \%)$ \\
$17-39$ years & $19(63.33 \%)$ \\
$40-70$ years & $19(63.33 \%)$ \\
Gender & $11(36.67 \%)$ \\
Male & $3(10 \%)$ \\
Female & $27(90 \%)$ \\
Body Mass Index $(\mathrm{BMI})$ & \\
Obese $\left(\mathrm{BMI}>25 \mathrm{~kg} / \mathrm{m}^{2}\right)$ & \\
Non-Obese $\left(\mathrm{BMI} \leq 25 \mathrm{~kg} / \mathrm{m}^{2}\right)$ & \\
\hline
\end{tabular}

Chi-square test showed that relationship between NLR of the $0^{\text {th }}$ day to the decrease in diaphragm thickness on the $3^{\text {rd }}$ day was not significant $(p=0.254$; Table 2$)$, while the decrease in diaphragm thickness on the $5^{\text {th }}$ day was significant $(\mathrm{p}=0.015$; Table 3$)$. 
ISSN 25980580

Table 2. Relationship between NLR and diaphragm thickness on $3^{\text {rd }}$ day

\begin{tabular}{ccccc}
\hline Variable & $\begin{array}{c}\text { Diaphragm } \\
\text { Thickness }<2 \mathrm{~mm}\end{array}$ & $\begin{array}{c}\text { Diaphragm } \\
\text { Thickness } \geq \\
2 \mathrm{~mm}\end{array}$ & $\begin{array}{c}\text { RR } \\
(95 \% \mathrm{CI})\end{array}$ & $p$ value \\
\hline NLR $>7$ & $4(22.22 \%)$ & $14(77.78 \%)$ & 0.53 & 0.254 \\
NLR $\leq 7$ & $5(41.67 \%)$ & $7(58.33 \%)$ & $(0.18-1.59)$ & \\
\hline Chi-square test $\mathrm{p}=0.05$ & &
\end{tabular}

Table 3. Relationship between NLR and diaphragm thickness on $5^{\text {th }}$ day

\begin{tabular}{ccccc}
\hline Variable & $\begin{array}{c}\text { Diaphragm } \\
\text { Thickness }<2 \\
\mathrm{~mm}\end{array}$ & $\begin{array}{c}\text { Diaphragm } \\
\text { Thickness } \geq 2 \\
\mathrm{~mm}\end{array}$ & $\begin{array}{c}\mathrm{RR} \\
(95 \% \mathrm{CI})\end{array}$ & $p$ value \\
\hline NLR $>7$ & $17(94.44 \%)$ & $1(5.56 \%)$ & $\begin{array}{c}1.62 \\
(0.99-2.64)\end{array}$ & 0.015 \\
$\mathrm{NLR} \leq 7$ & $7(58.33 \%)$ & $5(41.67 \%)$ & & \\
\hline
\end{tabular}

According to General Estimation Equation, subjects with higher NLR was associated with a significant higher risk of having decreased diaphragm thickness $(\mathrm{OR}=5.90 ; \mathrm{p}$-value $=$ $0.003)$.

\section{Discussion}

Mechanical ventilation (MV) is needed to maintain regular ventilation and oxygenation for patients with respiratory problems. Weaning from MV might fail due to several aspects and its failure is associated to the increased mortality risk. ${ }^{1}$ One of the reasons is decreased muscle mass of diaphragm due to Ventilator Induced Diaphragm Dysfunction (VIDD). The VIDD might occur due to three mechanisms, which are decreased process of protein synthesis, increased process of proteolysis, and oxidative stress. ${ }^{4}$ Muscle contractions have major role in the balance of protein synthesis. An increased activity of muscle contractions will stimulate protein synthesis whereas a decreased activity will reduce the synthesis. Decreased protein synthesis in patients with full support of MV probably occurs because myosin heavy-chain mRNA remains unchanged. ${ }^{14}$ Besides, significant muscular atrophy in critically ill patients is associated with alteration of gene expression related to muscle contraction. ${ }^{16}$

This study observed 48 subjects, though total of included subjects were only 30 . Participants in the study was dominated by male subjects $(63.33 \%)$ whereas the females were 
ISSN 25980580

only $36.67 \%$. Most of the subjects were aged 40-70 years old (63.33\%) whereas those aged 1739 years old were only $36.67 \%$. Subjects categorized as obese in the study were only $10 \%$ while $90 \%$ of them had body mass index (BMI) less than $25 \mathrm{~kg} / \mathrm{m}^{2}$. According to those data, the subjects seemed to be disproportional. Several factors might contribute to the thinning process of diaphragm muscle mass, especially in terms of age, gender, and body mass index. Though those factors might affect the interpretation, this study measured the changes in terms of range and its gradual process.

Critical patients commonly have major inflammatory process. The inflammation will disturb the protein synthesis and it will affect diaphragm muscle thickness. Inflammatory process can be detected by certain biomarkers, such as NLR. In this study, relationship between NLR of the $0^{\text {th }}$ day to the decrease in diaphragm thickness on the $3^{\text {rd }}$ day was not significant ( $p$ $=0.254$; Table 2), while the decrease in diaphragm thickness on the $5^{\text {th }}$ day was significant $(\mathrm{p}$ $=0.015$; Table 3). These tables did not only present the association between NLR and diaphragm thickness, but they also signified that NLR might increase gradually. This increase in NLR frequency might explain the process of mobilization and rapid migration of immune cells (neutrophils) from bone marrow into the circulation due to bacterial invasion. Neutrophilia is a phenomenon that occurs in systemic inflammation due to demarginated, delay of neutrophils' apoptosis, and stem-cell stimulation. ${ }^{17}$ On the other hand, decreased number of lymphocyte is caused by stress response that triggers the apoptotic process. ${ }^{18}$ Moreover, General Estimation Equation found that subjects with higher NLR (>7) was associated with a significant higher risk of having decreased diaphragm thickness.

Certain research suggested that NLR $($ AUC $=0.95)$ was useful and better than Creactive protein $(\mathrm{CRP})(\mathrm{AUC}=0.83)$. The present study supports that NLR could be a simple marker for infection with a good discrimination capacity as a predictor for bacteraemia in critical patients with infection. According to De Jager et al (2010), they concluded that NLR had a specificity of $63 \%$ and sensitivity of $77.2 \%$ to diagnose bacteremia.[12] It was considered as a better predictor than CRP levels (specificity 37\%, sensitivity 75\%), leukocytes (specificity $53.3 \%$, sensitivity 57.6\%), and neutrophils (sensitivity 57.6\%, specificity 59.8\%) serum. Yoon et al (2013) also found that the role of NLR $($ AUC $=0.95)$ was much better than CRP $($ AUC $=$ $0.83) .^{13}$ 
ISSN 25980580

This study had several limitations. First, samples in this study were limited and the demographic characteristics were disproportional. Second, the study utilized ultrasound examination to measure the diaphragm thickness. Ultrasound examination is quite subjective since the results might depend on the examiners' skills. Thus, these conditions might lead to insignificants results.

\section{Conclusion}

Neutrophil to lymphocyte ratio affected the decrease of diaphragm thickness in patients using mechanical ventilation.

\section{References}

1. Handayani D. Perbandingan Keberhasilan Menggunakan Integrative Weaning Index (IWI) dengan Rapid Shallow Breathing Index (RSBI) dalam proses penyapihan ventilasi mekanik [master's thesis]. FK UGM / RSUP Dr. Sardjito; 2017.

2. Marino P. Discontinuing mechanical ventilation. In: Marino's The ICU Book. 4th ed. Philadelphia: Lippincott Williams \& Wilkins; 2017.

3. Schepens T, Dianti J. Diaphragm protection: what should we target? Curr Opin Crit Care. 2020;26(1): 35-40. DOI: 10.1097/MCC.0000000000000683.

4. Xue Y, Zhang Z, Sheng CQ, Li YM, Jia FY. The predictive value of diaphragm ultrasound for weaning outcomes in critically ill children. BMC Pulm Med. 2019;19(1):270. DOI: 10.1186/s12890-019-1034-0.

5. Powers SK, Wiggs MP, Sollanek KJ, Smuder AJ. Ventilator-induced diaphragm dysfunction: cause and effect. Am J Physiol Regul Integr Comp Physiol. 2013;305:464-77. DOI: 10.1152/ajpregu.00231.2013.

6. Liu YY, Li LF. Ventilator-induced diaphragm dysfunction in critical illness. Exp Biol Med (Maywood). 2018;243(17-18):1329-37. DOI: 10.1177/1535370218811950.

7. Penuelas O, Keough E, Lopez-Rodriguez L, Carriedo D, Goncalves G, Barreiro E, et al. Ventilator-induced diaphragm dysfunction: translational mechanisms lead to therapeutical alternatives in the critically ill. Intensive Care Med Exp. 2019;7(Suppl 1):48. DOI: 10.1186/s40635-019-0259-9. 
ISSN 25980580

8. Kim WY, Suh HJ, Hong S, Koh Y, Lim C. Diaphragm dysfunction assessed by ultrasonography: influence on weaning from mechanical ventilation. 2011; 39(12):262730. DOI: 10.1097/CCM.0b013e3182266408.

9. Supinski GS, Morris PE, Dhar S, Callahan LA. Diaphragm dysfunction in critical illness. Chest. 2018;153(4):1040-51. DOI: 10.1016/j.chest.2017.08.1157.

10. Raheja R, Brahmavar M, Joshi D, Raman D. Application of lung ultrasound in critical care setting: a review. Cureus. 2019;11(7):e5233. iL

11. Jaber S, Petrof B, Jung B, Berthet J, Rabuel C. Rapidly Progressive Diaphragmatic Weakness and Injury during Mechanical Ventilation in Humans Rapidly Progressive Diaphragmatic Weakness and Injury during Mechanical Ventilation in Humans. Am J Respir Crit Care Med. 2011;183(3):364-71. DOI: 10.1164/rccm.201004-0670OC.

12. De Jager CP, van Wijk PT, Mathoera RB, de Jongh-Leuvenink J, van der Poll T, Wever PC. Lymphocytopenia and neutrophil-lymphocyte count ratio predict bacteremia better than conventional infection markers in an emergency care unit. Crit Care. 2010;14(5):192-9. DOI: $10.1186 /$ cc9309.

13. Yoon NB, Son C, Um SJ. Role of the neutrophil-lymphocyte count ratio in the differential diagnosis between pulmonary tuberculosis and bacterial community acquired pneumonia. Ann Lab Med. 2013;33(2):105-10. DOI: 10.3343/alm.2013.33.2.105

14. Singer M, Deutschman CS, Seymour CW, Shankar-Hari M, Annane D, Bauer M, et al. The third international consensus definitions for sepsis and septic shock (Sepsis-3). JAMA. 206;315(8):801-10. DOI: 10.1001/jama.2016.0287.

15. Ochala J, Gustafson A, Diez ML, Renaud G, Li M, Aare S, et al. Preferential skeletal muscle myosin loss in response to mechanical silencing in a novel rat intensive care unit model: underlying mechanisms. J Physiol. 2011;589(8):2007-26. DOI:10.1113/jphysiol.2010.202044.

16. Llano-Dize M, Fury W, Okamoto H, Bai Y, Gromada J, Larsson L. RNA-sequencing reveals altered skeletal muscle contraction, E3 ligases, autophagy, apoptosis, and chaperone expression in patients with critical illness myopathy. Skelet Muscle. 2019;9(1):9. DOI: 10.1186/s13395-019-0194-1. 
17. Terradas R, Graus S, Blanch J, Rium M, Saballs P. Eosinophil count and neutrophillymphocyte count ratio as prognostic markers in patients with bacteremia: a retrospective cohort study. PLoS One. 2012;7(8):e42860. DOI: 10.1371/journal.pone.0042860.

18. Chiarelli M, Achilli P, Tagliabue F, Brivio A, Airoldi A, Guttadauro A, et al. Perioperative lymphocytopenia predicts mortality and severe complications after intestinal surgery. Ann Transl Med. 2019;7(14):311. DOI: 10.21037/atm.2019.06.46. 